\title{
High Strain-Rate Compressive Behavior of Bulk Structural Adhesives: Epoxy and Methacrylate Adhesives*
}

\author{
Takashi YOKOYAMA**, Kenji NAKAI** and Norfazrina Hayati MOHD YATIM*** \\ ${ }^{* *}$ Department of Mechanical Engineering \\ Okayama University of Science, Okayama 700-0005, Japan \\ E-mail: yokoyama@mech.ous.ac.jp \\ ${ }^{* * * G r a d u a t e}$ School of Engineering \\ Okayama University of Science, Okayama 700-0005, Japan
}

\begin{abstract}
The present paper describes the determination of high strain-rate compressive stress-strain loops for bulk specimens of two different epoxy and methacrylate structural adhesives on the standard split Hopkinson pressure bar with a tapered striker bar. The full compressive stress-strain data including unloading process are obtained over a wide range of strain rates from $10^{-3}$ to $10^{3} / \mathrm{s}$ at room temperature. The effects of strain rate on the initial (secant) modulus, flow stress, dissipation energy and hysteresis loss ratio are studied. The experimental results show that both bulk structural adhesives exhibit highly strain-rate dependent viscoelastic behavior like polymeric materials.
\end{abstract}

Key words: Bulk Structural Adhesive, Compressive Stress-Strain Loop, Dynamic Viscoelasticity, Elastic After-Effect, Hopkinson Bar, Strain Rate, Strain Recovery

\section{Introduction}

Structural adhesive bonding has extensively been used in automotive, aircraft and railway industries; wide classes of components are assembled using adhesive joints. In order to ensure their structural integrity in service, we need to know the dynamic behavior of the adhesive joints, which is greatly affected by the mechanical response of both adherends and adhesives to dynamic loading. So far, the impact compressive ${ }^{(1)}$, tensile ${ }^{(2)}$, shear ${ }^{(3-7)}$ and torsional ${ }^{(8)}$ responses of the adhesive joints have often been determined on the drop-weight impact test apparatus or modified split Hopkinson pressure bar (SHPB) ${ }^{(9)}$. Numerical simulations of SHPB tests on double-lap adhesive joints were performed using the finite element technique to examine the effects of material and geometrical properties of adhesives and adherends, and striker-bar impact conditions on the accuracy of the SHPB method ${ }^{(10)}$. In an effort to isolate the effects of adherends and joint geometry on the dynamic response of the adhesive joints, the dynamic stress-strain properties of bulk structural adhesives were accurately evaluated in both tension and compression ${ }^{(11)}$. Recently, constitutive equations for bulk materials of structural adhesives have been proposed based on elasto-viscoplastic rheological models ${ }^{(12,13)}$. However, the dynamic stress-strain loops ${ }^{(14)}$ and associated energy dissipation in the bulk structural adhesives have not been fully understood yet.

The objective of the present work is to determine the high strain-rate compressive stress-strain behavior for bulk specimens of two different structural adhesives on the SHPB. Bulk structural adhesive sheets with a uniform thickness were fabricated by a special

*Received 1 July, 2011 (No. 11-0372) [DOI: 10.1299/jmmp.6.131]

Copyright (C) 2012 by JSME 
solidification procedure. Cylindrical specimens machined from the bulk adhesive sheets were tested at room temperature. The low and intermediate strain-rate compressive stress-strain data were obtained using an Instron testing machine. The influences of strain rate on the initial (secant) modulus, flow stress, dissipation energy and hysteresis loss ratio were discussed in detail. It is shown that both bulk structural adhesives evidently exhibit intrinsic strain-rate dependent viscoelastic behavior and an elastic after-effect ${ }^{(15)}$ following complete unloading like polymers.

\section{Experimental Details}

\subsection{Test Adhesives and Tensile Properties}

Commercially available two-part epoxy structural adhesive (thermoset), Scotch-Weld ${ }^{\circledR}$ DP-460 (Sumitomo 3M Limited, Japan) and methacrylate structural adhesive (thermoplastic), Plexus ${ }^{\circledR}$ MA560-1 (ITW PP\&F Japan Co., Ltd.) were chosen. The former is suitable for use with metallic adherends, and the latter is suitable for use with non-metallic (or composite and polymer) adherends. Both bulk adhesive sheets with almost no porosity were fabricated by a special solidification technique ${ }^{(16)}$ and cured for $24 \mathrm{hr}$ at room temperature, but not post-cured at higher temperatures. This is because the adherends to be joined do not tolerate high temperatures in industrial applications. Figure 1 gives a picture of two dumbbell-shaped specimens (JIS K7162) ${ }^{(17)}$ with a gage length of $50 \mathrm{~mm}$ machined from the bulk adhesive sheets with a thickness of $3 \mathrm{~mm}$. Tension tests were carried out in the Instron testing machine (Model 5500R) at a crosshead speed of $1 \mathrm{~mm} / \mathrm{min}$ (or strain rate of $3.3 \times 10^{-4} / \mathrm{s}$ ). Typical tensile properties of the two bulk adhesives including glass transition temperatures are listed in Table 1.

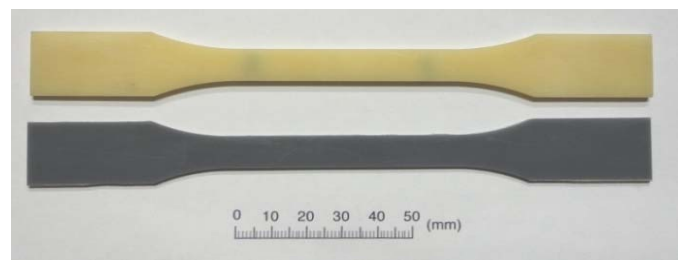

Fig.1 Picture of static sheet tension specimens of bulk structural adhesives: DP-460 (top) and MA560-1 (bottom)

Table 1 Nominal tensile and physical properties of two different bulk adhesives

\begin{tabular}{lcccc}
\hline Adhesive & $\begin{array}{c}\text { Initial modulus } \\
E[\mathrm{GPa}]\end{array}$ & $\begin{array}{c}\text { Tensile strength } \\
\sigma_{\mathrm{UTS}}[\mathrm{MPa}]\end{array}$ & $\begin{array}{c}\text { Elongation } \\
\varepsilon_{\mathrm{f}}[\%]\end{array}$ & $\begin{array}{c}\text { Glass Transition } \\
\text { Temperature } \\
T_{\mathrm{g}}[\mathrm{K}]\end{array}$ \\
\hline DP-460 & 2.1 & 44.1 & 8.9 & 331 \\
\hline MA560-1 & 0.7 & 12.6 & $\mathrm{~N} / \mathrm{A}^{* *}$ & 332 \\
\hline * defined as the secant modulus at $0.2 \%$ strain, & ${ }^{* *}$ not available $\left(\varepsilon_{\mathrm{f}}>100 \%\right)$
\end{tabular}

\subsection{Design of Compression Specimens}

Figure 2 shows cylindrical specimens machined out of the bulk adhesive sheets with a thickness of $5 \mathrm{~mm}$ as depicted in Fig. 3. Following the designation of ASTM E9-89a ${ }^{(18)}$, the slenderness ratio $l / d$ (= length/diameter) of the static specimen was taken as large as 1.875 by stacking three thin identical specimens to prevent barreling of the specimen due to end friction during compression loading. The slenderness ratio of the impact specimen was taken as 0.625 , falling in an appropriate slenderness ratio range between 0.5 and 1.0, suggested by Gray ${ }^{(19)}$ in the conventional SHPB tests (see, Table 2). 


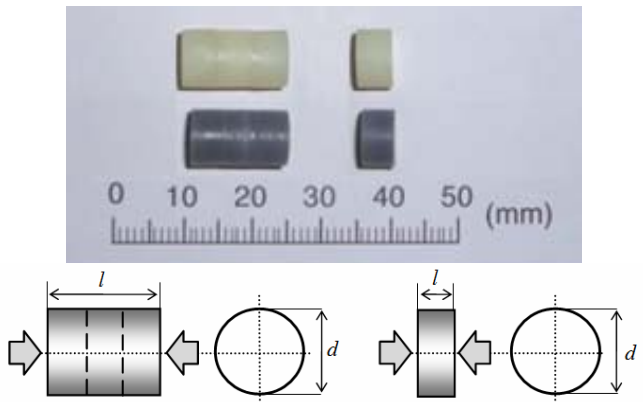

(a)

(b)

Fig.2 Picture of static and impact compression specimens: DP-460 (top); MA560-1 (bottom)

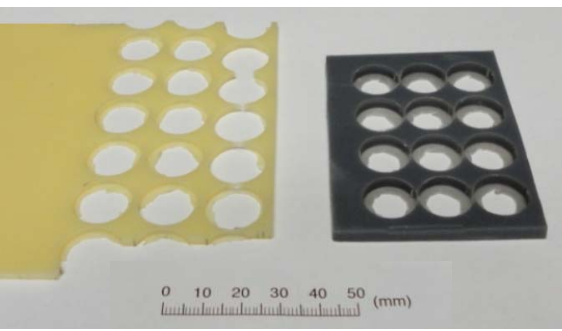

Fig.3 Picture of bulk adhesive sheets and locations of cylindrical specimen extraction: DP-460 (left) and MA560-1 (right)

Table 2 Nominal dimensions of static and impact compression specimens

\begin{tabular}{c|c|c|c}
\hline Strain rate & Length $l[\mathrm{~mm}]$ & Diameter $d[\mathrm{~mm}]$ & $\begin{array}{c}\text { Slenderness } \\
\text { ratio } l / d\end{array}$ \\
\hline \hline Static/Intermediate & 15 & 8 & 1.875 \\
\hline Impact & 5 & 8 & 0.625 \\
\hline
\end{tabular}

\subsection{Low / Intermediate Strain-Rate Compression Testing}

The low and intermediate strain-rate compression tests were conducted on the specimens with $l / d=1.875$ using the Instron testing machine at a crosshead speed of 1 $\mathrm{mm} / \mathrm{min}$ and $100 \mathrm{~mm} / \mathrm{min}$, respectively. Lubricant (or petroleum jerry) was applied to anvil/specimen interfaces to reduce the frictional effects. The specimens were loaded up to given strains and unloaded at the same two crosshead speeds. At least two repeatable tests were carried out at each crosshead velocity.

\subsection{High Strain-Rate Compression Testing}

A schematic of the SHPB apparatus ${ }^{(20)}$ is given in Fig. 4. The apparatus consists of two 2024-T4 Al alloy bars of $2000 \mathrm{~mm}$ in length and $10.1 \mathrm{~mm}$ in diameter. Instead of using a uniform striker bar, a tapered striker bar with a PEEK guide collar was used to generate constant strain-rate stress-strain data. A picture of the tapered striker bar is shown in Fig. 5.

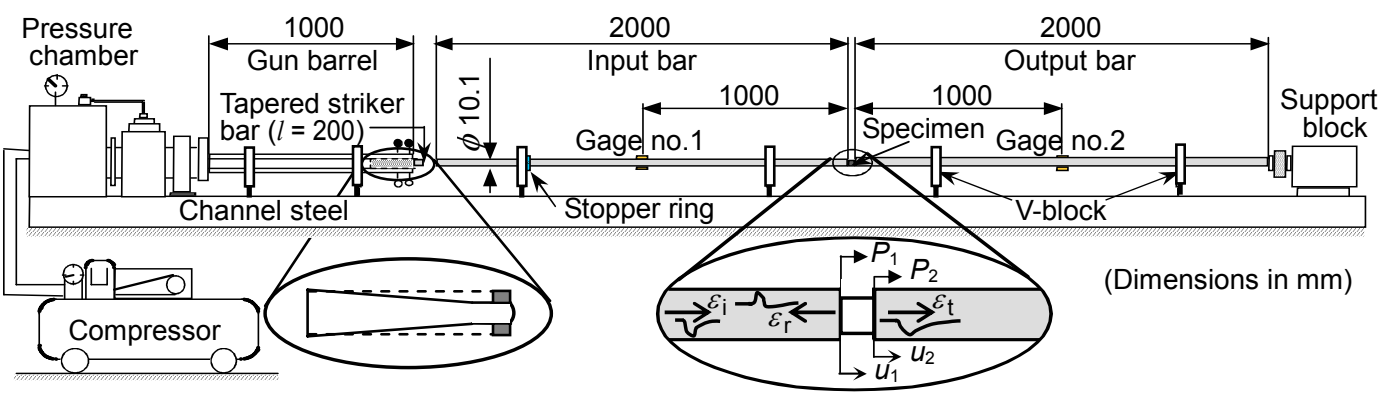

Fig.4 Schematic of conventional SHPB apparatus (associated recording system not shown) 

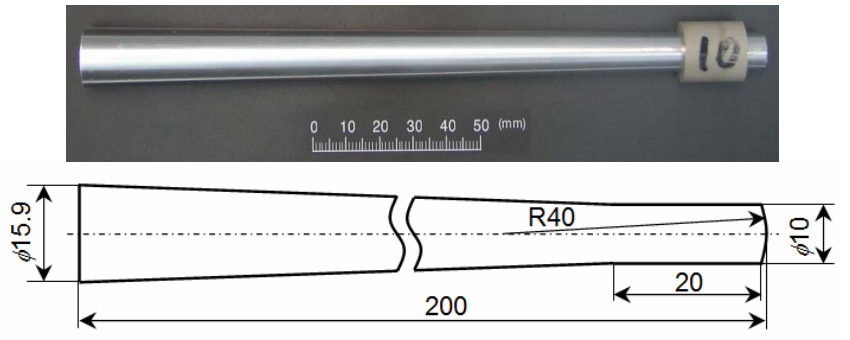

Fig. 5 Shape and dimensions of tapered striker bar

Table 3 Mechanical properties of striker, input and output bars used in SHPB system

\begin{tabular}{c|c|c|c}
\hline & Striker bar & Input bar & Output bar \\
\hline \hline Material & AA2017-T4 & AA2024-T4 \\
\hline Young's modulus $E(\mathrm{GPa})$ & 73 & 73 \\
\hline Longitudinal wave velocity $c_{0}(\mathrm{~m} / \mathrm{s})$ & 5120 & 5130 \\
\hline Yield strength $\sigma_{\mathrm{Y}}(\mathrm{MPa})$ & 405 & 450 \\
\hline
\end{tabular}



Fig.6 Lagrangian $x$ - $t$ diagram for SHPB test on bulk adhesives

The mechanical properties of the striker, input and output bars are listed in Table 3. Figure 6 depicts a Lagrangian $x$ - $t$ diagram illustrating the details of the elastic wave propagation in the input and output bars. The Al alloy bars with low impedance were used to reduce a drastic impedance mismatch between the bulk adhesive specimen and the conventional steel bars, which resulted in a transmitted strain signal with a very low signal-to-noise ratio. The specimen was held in place between the input and output bars by applying a very small pre-compression load with turning of the head of a support block. As in the static tests, lubricant (or petroleum jelly) was applied to the bar/specimen interfaces to reduce the frictional effects. A pulse shaping technique ${ }^{(21)}$ was applied to generate well-defined incident strain pulses without higher frequency components in the input bar. Namely, a 0.2 $\mathrm{mm}$ thick $1050 \mathrm{Al}$ disk of nearly $10 \mathrm{~mm}$ in diameter was attached onto the impact (left) end of the input bar using a thin layer of petroleum jelly. When the input bar was impacted with the tapered striker bar launched through the gun barrel, a compressive strain pulse $\left(\varepsilon_{i}\right)$ was generated in the input bar and travels towards the specimen. At the bar/specimen interface, because of the impedance mismatch, part of the strain pulse was reflected back into the 
input bar $\left(\varepsilon_{r}\right)$ and the remaining part was transmitted through the specimen into the output bar $\left(\varepsilon_{t}\right)$. The incident, reflect and transmitted strain pulses were then recorded with two pairs of strain gages mounted on the input and output bars. The output signals from the strain gages were fed through a bridge circuit into a 10-bit digital storage oscilloscope (Iwatsu: DS-9121), where the signals were digitized and stored at a sampling time of $1 \mu \mathrm{s} /$ word. The digitized data were then transferred to a 32-bit personal computer (PC-9821Xb: NEC) for data processing.

From the elementary one-dimensional theory of elastic wave propagation, we can determine the nominal strain $\varepsilon(t)$, strain rate $\dot{\varepsilon}(t)$ and stress $\sigma(t)$ in the specimen from the SHPB test records as ${ }^{(22)}$

$$
\begin{aligned}
& \varepsilon(t)=\frac{u_{1}(t)-u_{2}(t)}{l}=\frac{2 c_{\mathrm{o}}}{l} \int_{0}^{t}\left\{\varepsilon_{i}\left(t^{\prime}\right)-\varepsilon_{t}\left(t^{\prime}\right)\right\} \mathrm{d} t^{\prime} \\
& \dot{\varepsilon}(t)=\frac{\dot{u}_{1}(t)-\dot{u}_{2}(t)}{l}=\frac{2 c_{\mathrm{o}}}{l}\left\{\varepsilon_{i}(t)-\varepsilon_{t}(t)\right\} \\
& \sigma(t)=\frac{P_{2}(t)}{A_{\mathrm{S}}}=\frac{A E}{A_{\mathrm{S}}} \varepsilon_{t}(t)
\end{aligned}
$$

Here $u$ and $P$ are the displacement and the axial force on both ends of the specimen, respectively, (see the inset in Fig. 4); $A$ and $E$ are the cross-sectional area and Young's modulus of the Hopkinson (2024-T4 Al alloy) bars; $A_{\mathrm{s}}$ is the cross-sectional area of the specimen. Equations (1) to (3) are derived under the assumption of dynamic force equilibrium across the specimen, which can be expressed as

$$
P_{1}(t)=P_{2}(t) \text { or } \varepsilon_{i}(t)+\varepsilon_{r}(t)=\varepsilon_{t}(t)
$$

where

$$
P_{1}(t)=A E\left[\varepsilon_{i}(t)+\varepsilon_{r}(t)\right], \quad P_{2}(t)=A E \varepsilon_{t}(t)
$$

In the above derivations, the incident and reflected strain pulses are time-shifted to the specimen-input bar interface, and the transmitted strain pulse is time-shifted to the specimen-output bar interface (see, Fig.6). Eliminating time $t$ through Eqs. (1) to (3) yields the nominal (or engineering) compressive stress-strain and strain rate-strain relations. In this work, the compressive stress and strain are taken as positive.

\section{Results and Discussion}

\subsection{SHPB Tests}

A number of the SHPB tests were conducted on the bulk adhesive specimens at room temperature. Figure 7 indicates typical oscilloscope traces of incident and reflected strain pulses $\left(\varepsilon_{i}\right.$ and $\left.\varepsilon_{r}\right)$ and transmitted strain pulse $\left(\varepsilon_{t}\right)$ from the SHPB test on the epoxy adhesive DP-460. The recorded signal data are neither smoothed nor averaged electronically. Note that the duration $(\fallingdotseq 400 \mu \mathrm{s})$ of the reflected and transmitted strain pulses is much longer than that $(\fallingdotseq 250 \mu \mathrm{s})$ of the incident strain pulse. This is because it takes much time for the specimen stress to decay to zero due to relaxation phenomena (see, Fig. 9), causing often the overlapping between the transmitted strain pulse and its strain pulse reflected from the free (or right) end of the output bar. In the present tests, the overlapping of the two strain pulses is successfully avoided by the use of the long output bar. Figure 8 gives the resulting axial stress histories at the front and back ends of the specimen. The nearly overlapping histories clearly indicate that dynamic stress equilibrium (stress uniformity) is achieved in 
the specimen over the entire duration of loading. Figure 9 shows the dynamic compressive stress and strain histories for the epoxy adhesive DP-460. Note that the dynamic strain history lags behind the dynamic stress history during loading and unloading, suggesting typical viscoelastic retardation effects.

Figure 10 presents the resulting dynamic stress-strain and strain rate-strain loops in compression for the epoxy adhesive DP-460. The strain-rate flips its sign from compression (loading) to tension (unloading) at the peak of the loading strain. The strain rates $\dot{\varepsilon}=920 / \mathrm{s}$ and $\dot{\varepsilon}=-300 /$ s given, respectively, denote the average strain rates during loading and unloading process. As in the low and intermediate strain rate tests, the dynamic stress-strain loop is not closed, and consequently, a residual strain of about 0.02 is not completely recovered to zero in time.

Figures 11 and 12 show the compressive stress-strain loops for the two different bulk adhesives at three different strain rates. The initial slope (or initial modulus $E$ ) and the area within the loop for both adhesives increase greatly with increasing strain rate. Furthermore, initial residual strains after complete unloading are found to decrease with increasing strain rate for the epoxy adhesive DP-460, but to remain almost unvaried for the methacrylate adhesive MA560-1. The strain-rate dependent stress-strain behavior for both bulk adhesives is consistent with that for the bulk epoxy adhesive Hysol $9466^{(12)}$, determined using the SHPB.

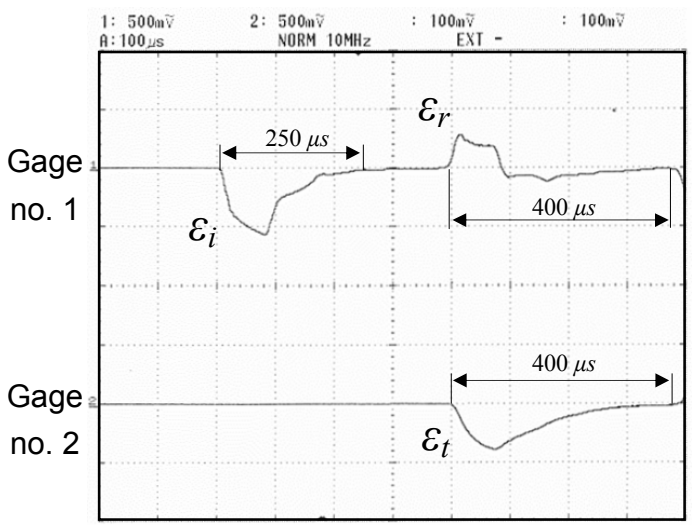

Sweep rate: $100 \mu \mathrm{s} / \mathrm{div}$ Vertical sensitivity:

Upper trace: $500 \mathrm{mV} / \mathrm{div}(1266 \mu \varepsilon / \mathrm{div})$ Lower trace: $500 \mathrm{mV} / \mathrm{div}(1274 \mu \varepsilon / \mathrm{div})$

Fig.7 Oscilloscope records of incident, reflected and transmitted signals in SHPB test on epoxy adhesive DP-460 $\left(V_{\mathrm{s}}=15.4 \mathrm{~m} / \mathrm{s}\right)$

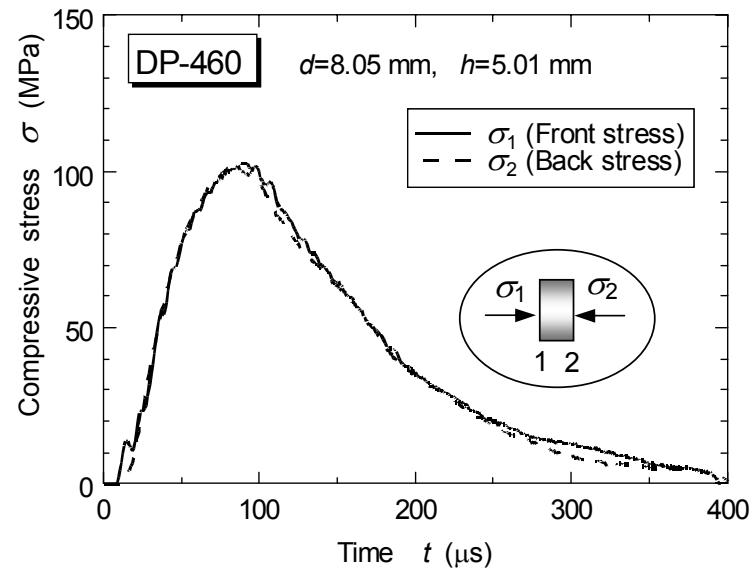

Fig.8 Front and back stress histories on each face of epoxy adhesive DP-460 specimen 


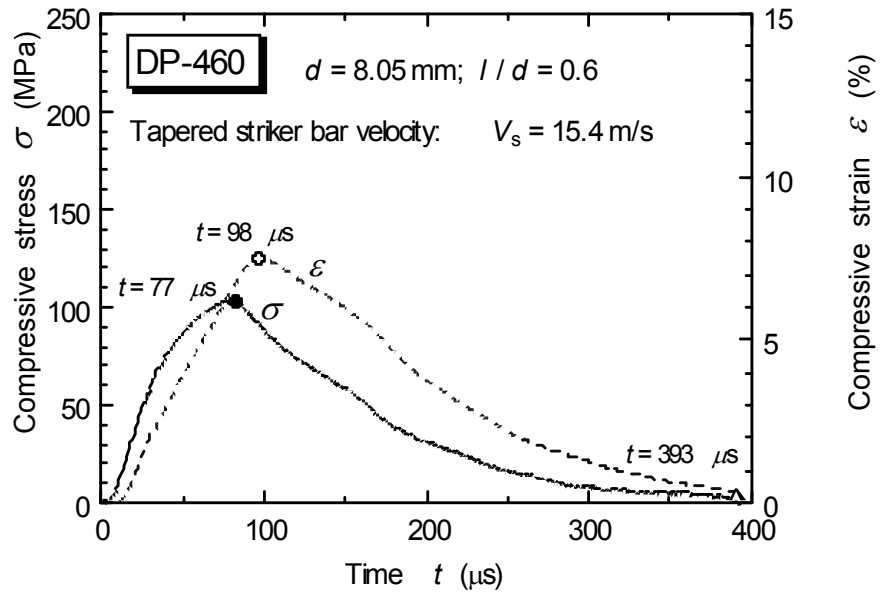

Fig.9 Dynamic stress and strain histories for epoxy adhesive DP-460

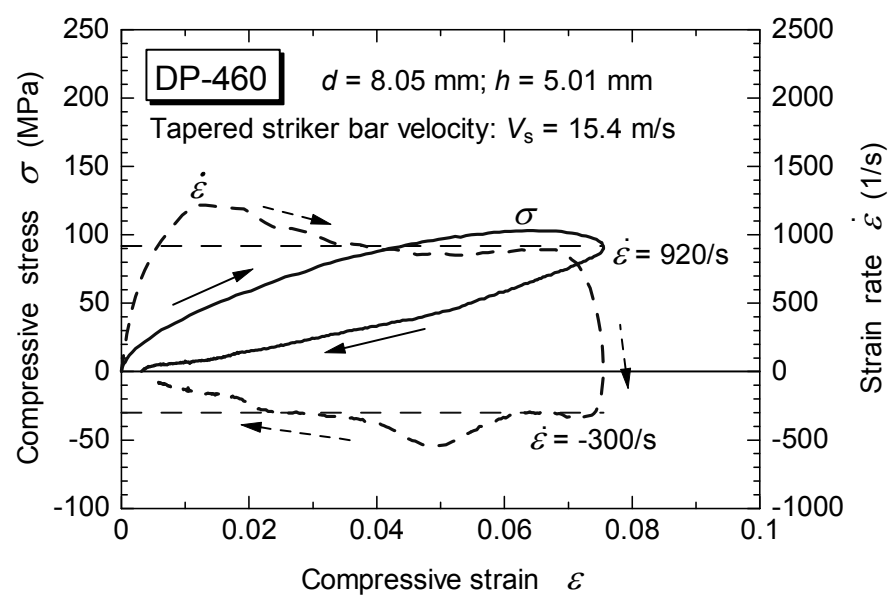

Fig.10 Dynamic compressive stress-strain (solid line) and strain rate-strain (dashed line) loops for epoxy adhesive DP-460

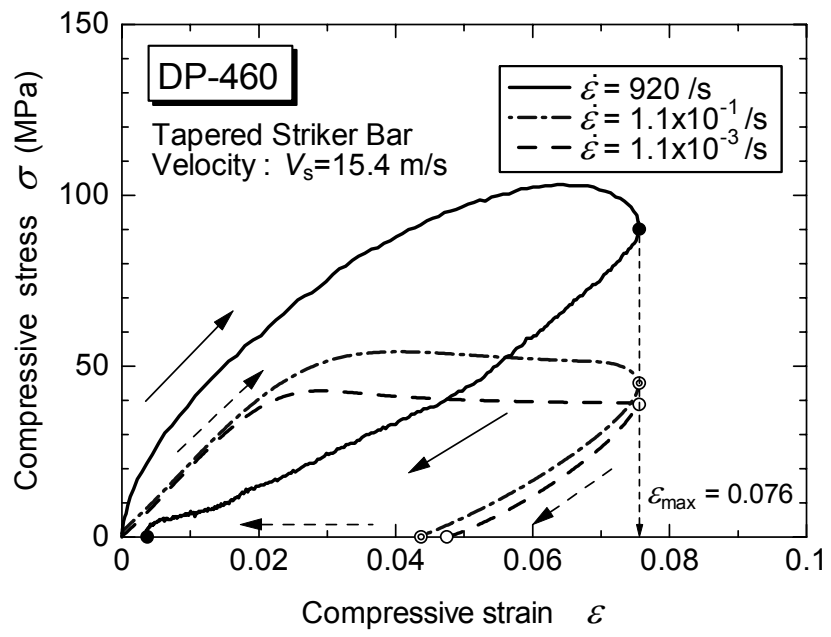

Fig.11 Compressive stress-strain loops at three different strain rates for epoxy adhesive DP-460 (solid, double and open circles marked on horizontal axis indicate initial residual strains) 


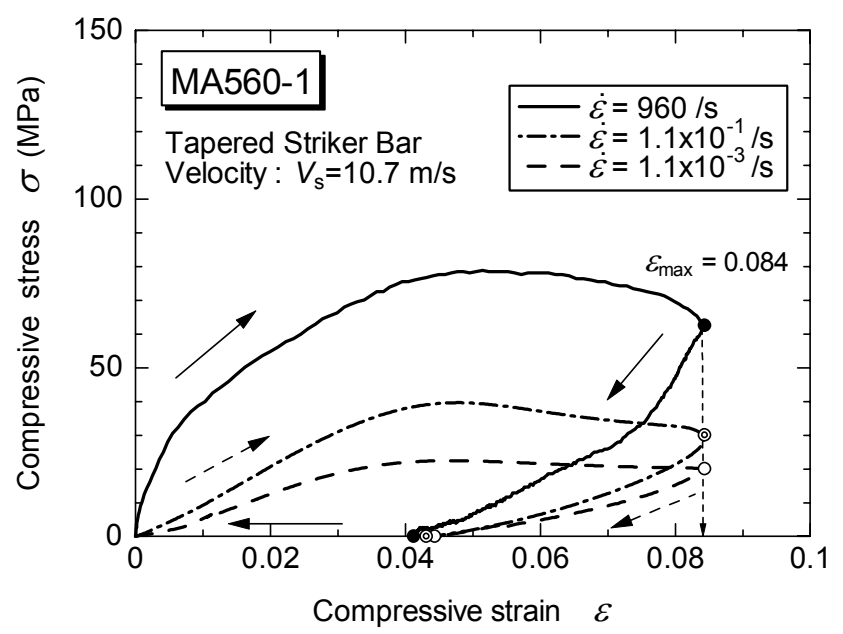

Fig.12 Compressive stress-strain loops at three different strain rates for methacrylate adhesive MA560-1 (see key in Fig. 11)

\subsection{Strain-Rate Dependence}

In order to evaluate the effects of strain rate on the compressive properties of the two different bulk adhesives, the measured values for the initial modulus (as the secant modulus at 0.002 strain), flow stress at given strains of 0.02 and 0.04 , dissipation energy and hysteresis loss ratio up to $\varepsilon_{\max } \fallingdotseq 0.076$ and 0.084 are plotted in Figs. 13 to15 against the average strain rate. As seen from Fig. 10, the initial strain rate in the strain rate-strain loop is much smaller than the average strain rate during loading. Therefore, the average strain rate associated with the initial modulus is estimated from the area under the strain rate-strain relation up to 0.002 strain divided by 0.002 . Figure 16 illustrates that the dissipation energy (= hysteresis loss) $U_{\mathrm{d}}$ is defined as the area within the stress-strain loop. The hysteresis loss ratio $H_{\mathrm{e}}{ }^{(23)}$ is then calculated as the ratio of the hysteresis loss $U_{\mathrm{d}}$ to the area $W$ under the stress-strain curve during loading. The initial modulus, flow stress at given strains of 0.02 and 0.04 and dissipation energy increase significantly with increasing strain rate for both adhesives. In contrast, the hysteresis loss ratio for the epoxy adhesive DP-460 significantly decreases with increasing strain rate, while that for the methacrylate adhesive MA560-1 remains almost unchanged. The dissipation energy is mostly converted to heat during high rate deformation, causing the adiabatic temperature rise within the specimen.

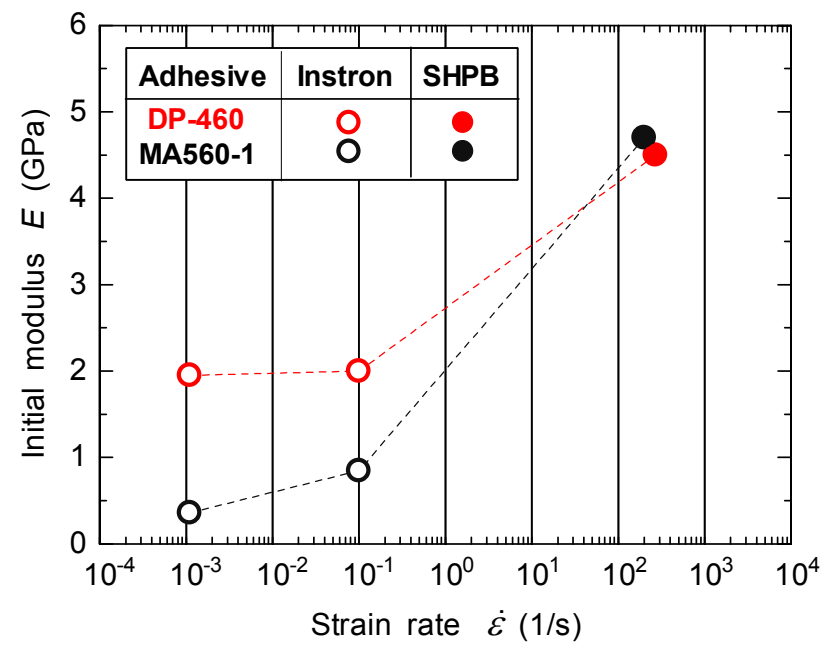

Fig.13 Effect of strain rate on initial modulus for two different bulk adhesives 


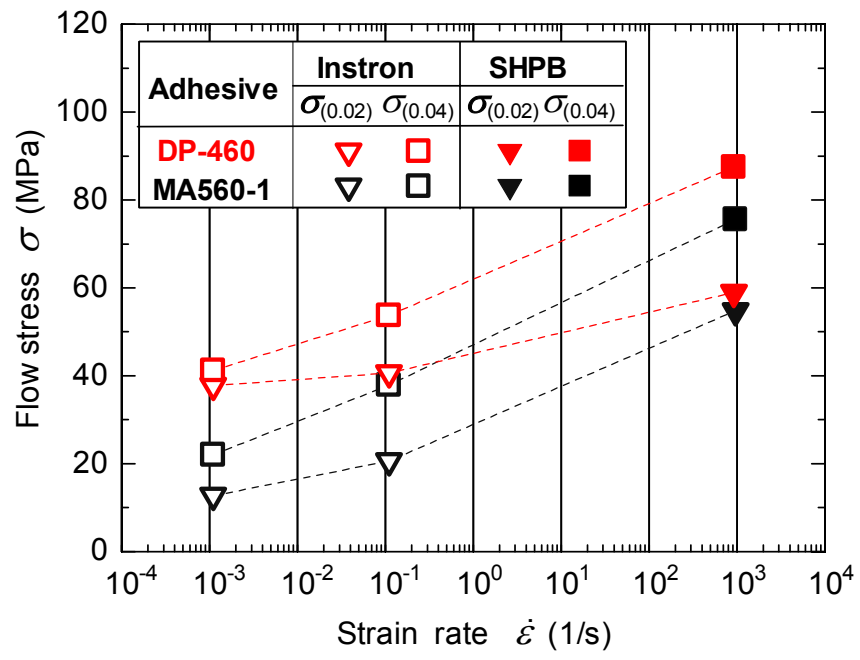

Fig.14 Effect of strain rate on flow stress at given strains of 0.02 and 0.04 for two different bulk adhesives

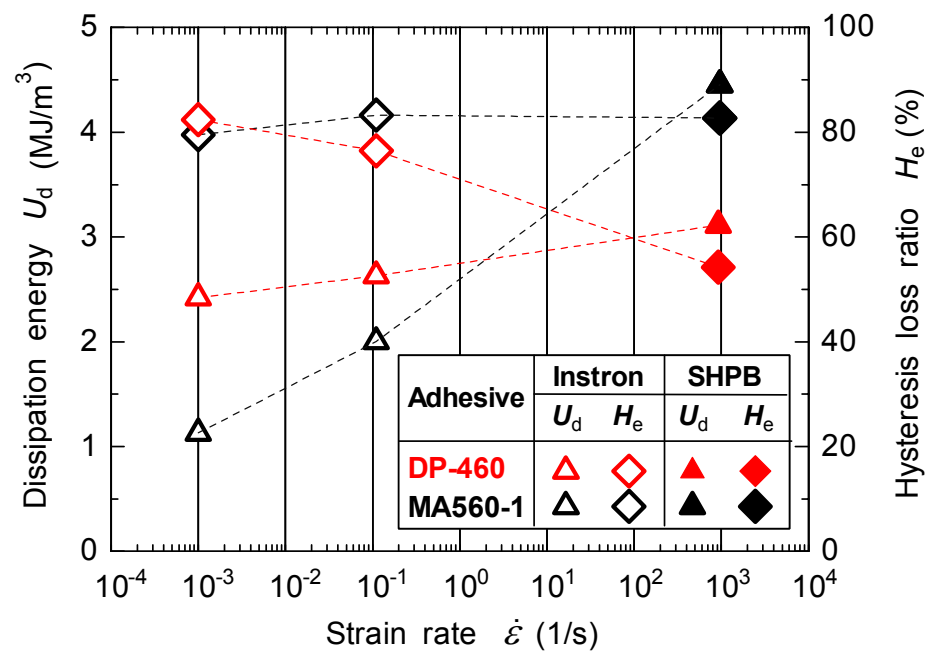

Fig. 15 Effect of strain rate on dissipation energy and hysteresis loss ratio up to maximum strain $\varepsilon_{\max } \fallingdotseq 0.08$ for two different bulk adhesives

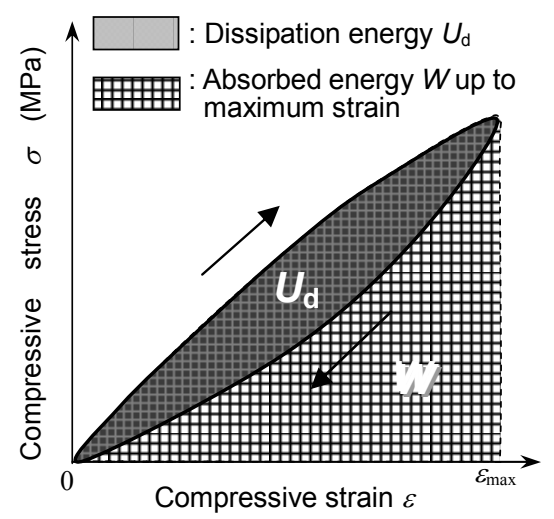

Hysteresis loss ratio $H_{e}=\left(U_{d} / W\right) \times 100(\%)$

Fig.16 Schematic illustration of dissipation energy and hysteresis loss ratio under stress-strain curve up to maximum strain $\varepsilon_{\max }$ 
In an attempt to quantitatively evaluate the rate dependence of the flow stress, two different strain-rate sensitivity parameters $\beta$ and $n^{(24)}$ are introduced. The two parameters estimated for the respective bulk adhesives are summarized in Table 4, where $\sigma_{1}$ and $\sigma_{2}$ are stresses at the average strain rates $\dot{\varepsilon}_{1}$ and $\dot{\varepsilon}_{2}$, respectively, for the fixed two values of $\varepsilon=0.02$ and 0.04. It is obvious that the methacrylate adhesive MA560-1 exhibits much higher strain-rate sensitivity than the epoxy adhesive DP-460, irrespective of prescribed strains. The two parameters $\beta$ and $n$ are not constant, and dependent on the strain as well as on the strain rate. However, these parameters are useful as a measure of the strain-rate sensitivity.

Table 4 Strain-rate sensitivity parameters for two different bulk adhesives within a range of strain rates from $\dot{\varepsilon}_{1}=1.1 \times 10^{-3} / \mathrm{s}$ to $\dot{\varepsilon}_{2} \cong 10^{3} / \mathrm{s}$

\begin{tabular}{|c|c|c|c|c|}
\hline \multirow{3}{*}{ Adhesive } & $\beta=\frac{\sigma_{2}}{\log (\dot{\varepsilon}}$ & \multirow[t]{2}{*}{$\begin{array}{l}{[\mathrm{MPa}]} \\
\varepsilon=\varepsilon_{0}\end{array}$} & \multirow{2}{*}{$\begin{array}{r}n=\frac{\log \left(\sigma_{2} / \sigma_{1}\right)}{\log \left(\dot{\varepsilon}_{2} / \dot{\varepsilon}_{1}\right)} \\
\dot{\varepsilon}_{2}>\dot{\varepsilon}\end{array}$} & \multirow[t]{2}{*}{$\begin{array}{l}{[-]} \\
\varepsilon=\varepsilon_{0}\end{array}$} \\
\hline & $\dot{\varepsilon}_{2}>\dot{\varepsilon}_{1}$ & & & \\
\hline & $\varepsilon_{\mathrm{O}}=0.02$ & $\varepsilon_{\mathrm{o}}=0.04$ & $\varepsilon_{\mathrm{o}}=0.02$ & $\varepsilon_{\mathrm{o}}=0.04$ \\
\hline DP-460 & 3.56 & 7.82 & 0.033 & 0.055 \\
\hline MA560-1 & 7.09 & 9.02 & 0.107 & 0.090 \\
\hline
\end{tabular}

\subsection{Strain Recovery and Elastic After-Effect}

We now consider the time dependence of strain recovery at different unloading strain rates. As seen in Fig.11, the amount of initial residual strains after complete unloading varies, depending on the strain rate when the maximum loading strain is almost the same $\left(\varepsilon_{\max }=0.076\right)$. The initial residual strain slowly decays to nearly zero in time, whose behavior is known as an elastic after-effect ${ }^{(16)}$, inherent to polymeric materials. Figures 17 and 18 show the histories of recovery strains during unloading and the initial residual strains at three different unloading strain rates. The horizontal axis indicates the time after the start of unloading on each stress-strain curve (note that for convenience sake, the origin on a logarithmic time scale is set equal to $1 \mu \mathrm{s}$ ). The strains at a start point on the dashed lines correspond to each initial residual strain just after unloading. Arrows on the dashed lines indicate the phenomenon of "elastic after-effect". The residual strains at 120 and 300 seconds after complete unloading were precisely determined through measurements of the specimen length with a digital sliding caliper (Mitutoyo Corp., Model CD-15C).

The initial residual strains in the DP-460 get smaller with increasing unloading strain rates, whereas those in the MA560-1 are recovered to nearly the same value of strain, independent of the unloading strain rates. This different strain recovery behavior may arise from differences in the molecular structures between the thermosetting adhesive (DP-460) and the thermoplastic adhesive (MA560-1). Thermosetting adhesives are composed of cross-linked long-chain molecules, unlike the thermoplastic adhesives. As seen from Figs. 13 and 14, the cross-linked adhesive (DP-460) exhibits higher stiffness and strength than the thermoplastic adhesive (MA560-1). Nevertheless, why the thermosetting adhesive (DP-460) shows the unloading strain-rate dependence of initial residual strains is not clear at present. A similar unloading strain-rate dependence of initial residual strains was also reported by Yi, et $a l^{(25)}$ on a thermosetting polyurea at strain rates ranging from $10^{-3}$ to $1 / \mathrm{s}$. Further study is required to elucidate the effect of strain rate history on the strain recovery process in the bulk adhesives. 


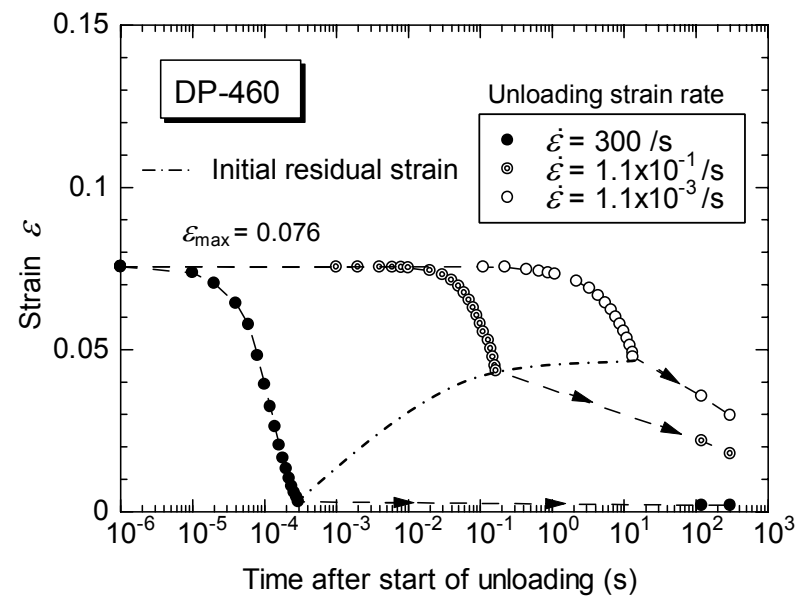

Fig.17 Histories of recovery strains during unloading and initial residual strains at three different unloading strain rates within epoxy adhesive DP-460 specimen

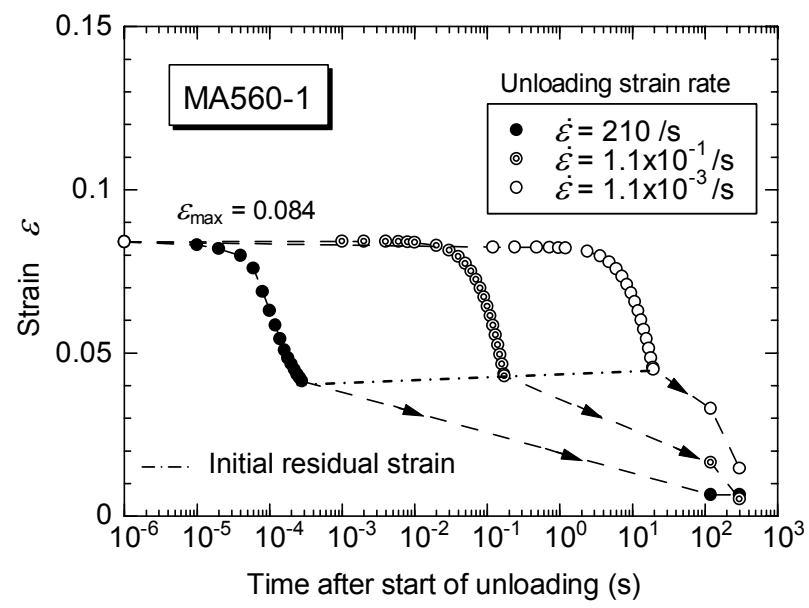

Fig. 18 Histories of recovery strains during unloading and initial residual strains at three different unloading strain rates within methacrylate adhesive MA560-1 specimen

\section{Summary and Conclusions}

The influences of strain rate on the compressive stress-strain loops for the two different bulk adhesives DP-460 and MA560-1 for structural bonding have been investigated using the conventional SHPB with the tapered striker bar. The effects of strain rate on the amount of the initial residual strains in the compression specimen were also examined under almost the same maximum loading strain conditions. From this experimental work, we can draw the following conclusions:

1) The two different bulk adhesives exhibit intrinsic dynamic viscoelastic behavior and a slight "elastic after-effect" following complete unloading like polymers.

2) The initial (secant) modulus, flow stress at fixed strains and dissipation energy for the two different adhesives increase greatly with increasing strain rate.

3) The hysteresis loss ratio for the DP-460 becomes lower than that for the MA560-1 at higher strain rates, implying that the former is more excellent than the latter in the hysteresis loss performance.

4) The MA560-1 shows even higher strain-rate sensitivity than the DP-460. 
5) The amount of the initial residual strains for the DP-460 after complete unloading varies, depending on the unloading strain rate when the maximum loading strain is almost the same.

6) The use of the tapered striker bar in the SHPB tests is effective for obtaining valid dynamic stress-strain data at nearly constant strain rates.

The use of the two structural adhesives should be selected properly for any purpose of adhesive bonding, considering their dynamic features. Further work is needed to examine the effect of temperature as well as strain rate on the stress-strain behavior of both bulk structural adhesives.

\section{Acknowledgement}

The third author, Norfazrina Hayati MOHD YATIM (currently on leave from IIUM), wishes to acknowledge the support provided by the International Islamic University Malaysia (IIUM) and by WESCO Scientific Promotion Foundation, Okayama, Japan. Thanks are also due to Professor C. Sato of Tokyo Institute of Technology for his kind advice on a fabrication process for the bulk adhesive sheets with a uniform thickness.

\section{References}

[1] Martínez, M.A., Chocron, I.S., Rodríguez, J., Sánchez Gálvez, V. and Sastre, L.A., "Confined Compression of Elastic Adhesives at High Rates of Strain," Int. J. Adhes. Adhes., Vol. 18, (1998), pp. 375-383.

[2] Yokoyama, T., "Experimental Determination of Impact Tensile Properties of Adhesive Butt Joints with the Split Hopkinson Bar," J. Strain Analysis, Vol. 38, (2003), pp. 233-245.

[3] Yokoyama, T. and Shimizu, H., "Evaluation of Impact Shear Strength of Adhesive Joints with the Split Hopkinson Bar,” JSME Int. J. Ser. A, Vol. 41, (1998), pp. 503-509.

[4] Bezemer, A.A., Guyt, C.B. and Vlot, A., "New Impact Specimen for Adhesives: Optimization of High-Speed-Loaded Adhesive Joints," Int. J. Adhes. Adhes., Vol. 18, (1998), pp. 255-260.

[5] Srivastava, V., Shukla, A. and Parameswaran, V., "Experimental Evaluation of Dynamic Shear Strength of Adhesive-Bonded Lap Joints," J. Test. Eval. Vo1.28, (2000), pp.438-442.

[6] Adamvalli, M. and Parameswaran, V., "Dynamic Strength of Adhesive Single Lap Joints at High Temperature," Int. J. Adhes. Adhes., Vol. 28, (2008), pp. 321-327.

[7] Challita, G., Othman, R., Casari, P. and Khalil, K., "Experimental Investigation of the Shear Dynamic Behavior of Double-Lap Adhesively Bonded Joints over a Wide Range of Strain Rates", Int. J. Adhes. Adhes., Vol. 31, (2011), pp. 146-153.

[8] Raykhere S. L., Kumar, P., Singh, R.K. and Parameswaran, V., "Dynamic Shear Strength of Adhesive Joints Made of Metallic and Composite Adherents," Mater. Design., Vol. 31, (2010), pp. 2102-2109.

[9] Kolsky, H., “An Investigation of the Mechanical Properties of Materials at Very High Rates of Loading,” Proc. Phys. Soc., Vol. B62, (1949), pp. 676-700.

[10] Challita, G. and Othman, R., "Finite-Element Analysis of SHPB Tests on Double-Lap Adhesive Joints", Int. J. Adhes. Adhes., Vol. 30, (2010), pp. 236-244.

[11] Goglio, L., Peroni, L., Peroni, M. and Rossetto, M., "High Strain-Rate Compression and Tension Behaviour of an Epoxy Bi-Component Adhesive," Int. J. Adhes. Adhes., Vol. 28, (2008), pp. 329-339. 
[12] Fancello, E., Goglio, L., Stainier, L. and Vassoler, J.M., "Identification of the Strain Rate Parameters for Structural Adhesives," J. Adhesion Sci. Technol., Vol. 22, (2008), pp. 1523-1540.

[13] Iwamoto, T., Nagai, T. and Sawa, T., "Experimental and Computational Investigations on Strain Rate Sensitivity and Deformation Behavior of Bulk Materials Made of Epoxy Resin Structural Adhesive," Int. J. Solids \& Struct., Vol. 47, (2010), pp. 175-185.

[14] Song, B. and Chen, W., "Loading and Unloading Split Hopkinson Pressure Bar Pulse-Shaping Techniques for Dynamic Hysteretic Loops,” Exp. Tech., (2004), Vol. 44, pp. 622-627.

[15] Dieter, G.E., Mechanical Metallurgy, (1988), SI Metric Edition, McGraw-Hill, London, p. 434.

[16] French Standard NF T76-14, Preparation method of structural adhesives plates for characterization test pieces, (1998), (in French).

[17] JIS K7162, 2010, JIS Handbook-26, Plastics I, The Japanese Standards Association, p. 428.

[18] ASTM E9-89a, 1995, Annual Book of ASTM Standards, Section 3, Vol. 03.01, ASTM, pp. 98-105.

[19] Gray, III, G. T., Classic Split-Hopkinson Pressure Bar Testing, ASM Handbook Vo.8, Mechanical Testing and Evaluation, ASM International, p.471.

[20] Nakai, K. and Yokoyama, T., "Strain Rate Dependence of Compressive Stress-Strain Loops of Several Polymers,” J. Solid Mech. Mater. Eng., Vol. 2, (2008), pp. 557-566.

[21] Frew, D.J., Forrestal, M.J. and Chen, W., "Pulse Shaping Techniques for Testing Brittle Materials with a Split Hopkinson Pressure Bar”, Exp. Mech., Vol.42, (2002), pp. 93-106.

[22] Lindholm, U.S., "Some Experiments with the Split Hopkinson Pressure Bar," J. Mech. Phys. Solids, Vol. 12, (1964), pp. 317-335.

[23] JIS K7312, 2010, JIS Handbook-26, Plastics I, The Japanese Standards Association, p. 2451.

[24] Malatyński, M. and Klepaczko, J., "Experimental Investigation of Plastic Properties of Lead over a Wide Range of Strain Rates," Int. J. Mech. Sci., Vol. 22, (1980), pp. 173-183.

[25] Yi, J., Boyce, M.C., Lee, G.F. and Balizer, E., "Large Deformation Rate-Dependent Stress-Strain Behavior of Polyurea and Polyurethanes," Polymer, Vol. 47, (2006), pp. 319-329. 